DOI: $10.12957 /$ teias.2022.51239

\title{
(IN)DISCIPLINA E VISIBILIDADE: considerações sobre ambiguidades e tensões no ambiente escolar
}

\section{Leonardo H. B. Monteiro}

Resumo

O paper se dedica a refletir sobre a lógica (in)disciplina e suas corporificações no ambiente escolar. Intenta traçar uma linha de inteligibilidade que permita compreender os comportamentos estudantis lidos como indisciplinados pelos profissionais escolares, bem como, a forma pela qual estes comportamentos acabam se conectando e (re)atualizando esta lógica. A metodologia deste trabalho engloba a discussão de dados empíricos retirados de uma etnografia e de entrevistas semiestruturadas com atores escolares, de forma a articular estes dados com uma reflexão bibliográfica. Discute-se as dimensões dos comportamentos lidos como indisciplinados de modo a não os alocar automaticamente ao polo da resistência, e sim, de problematizar esta alocação. Também se aponta a importância de considerarmos questões que envolvem dinâmicas de prazer/poder entre os polos de normalização/resistência, assim como, a existência de um jogo entre o ver e ser visto existente na escola, na qual os comportamentos classificados como indisciplinados são centrais. Estas reflexões nos levarão a concluir que a existência da escola no modelo disciplinar como conhecemos hoje persiste dentro da lógica (in)disciplina, pois ao mesmo tempo que esta desloca feixes de poder dentro da instituição, esta reforça a escola, enquanto instituição, a todo momento.

Palavras-chave: disciplina escolar; indisciplina escolar; micropolítica; ver/ser visto; prazer/poder.

(IN)DISCIPLINE AND VISIBILITY: considerations about tensions and ambiguities in the school

\begin{abstract}
This paper is dedicated to think on the logic (in) discipline and its embodiments in the school environment. It attempts to draw an intelligibility line that allows understanding student behaviors read as undisciplined by school professionals, as well as the way in which these behaviors end up connecting and (re)updating this logic. The methodology of this work includes the discussion of empirical data taken from an ethnography and semi-structured interviews with school actors. These data will be articulate with a bibliographic review. The dimensions of the behaviors read as undisciplined are discussed in order not to automatically allocate them to the pole of resistance, but to problematize this allocation. It also points out the importance of considering issues involving pleasure/power dynamics between the poles of normalization/resistance, as well as the existence of a game between seeing and being seen existing at school, in which the behaviors classified as undisciplined are central. These reflections will lead us to conclude that the existence of the school in the disciplinary model as we know it today persists within the (in)discipline logic, because at the same time that it dislocates bundles of power within the institution, it reinforces the school, as an institution, at all time.
\end{abstract}

Keywords: school discipline; school indiscipline; micropolitics; see/be seen; pleasure/power.

(IN)DISCIPLINA Y VISIBILIDAD: consideraciones sobre tensiones y ambigüedades en la escuela

\section{Resumen}

Este artículo está dedicado a reflexionar sobre la lógica (in)disciplina y sus actuaciones en el medio escolar. Intenta dibujar una línea de inteligibilidad que permita comprender los comportamientos de los estudiantes leídos como no disciplinados por los profesionales de la escuela, así como la forma en que estos 
comportamientos terminan conectando y (re)actualizando a esta lógica. La metodología de este trabajo incluye la discusión de datos empíricos tomados de una etnografía y entrevistas semiestructuradas con actores escolares, con el fin de articular estos datos con una reflexión bibliográfica. Las dimensiones de los comportamientos leídos como indisciplinados se discuten para no asignarlos automáticamente al polo de resistencia, sino para problematizar esta asignación. También se señala la importancia de considerar cuestiones que involucran dinámicas de placer/poder entre los polos de normalización/resistencia, así como la existencia de un juego entre ver y ser visto existente en la escuela, en el que los comportamientos clasificados como indisciplinados son centrales. Estas reflexiones nos llevarán a la conclusión de que la existencia de la escuela en el modelo disciplinario tal como la conocemos hoy persiste dentro de la lógica (in)disciplinaria, porque al mismo tiempo que disloca los paquetes de poder dentro de la institución, refuerza la escuela, como institución.

Palabras clave: disciplina escolar; indisciplina escolar; micropolítica; ver/ser visto; placer/poder.

\section{INTRODUÇÃO}

A escola é um local de tensão social perene e que comporta uma gama gigantesca de ambiguidades. Consideremos, por ora, uma peça audiovisual ${ }^{1}$, na qual as vivências do mundo escolar se reproduzem de forma ficcional. Em cena do seriado televisivo estadunidense "Os Simpsons", o personagem Bart, uma criança de dez anos, sonha com seu último dia de aula antes das férias escolares. No trecho do seriado em questão há a destruição da escola e de materiais escolares promovida por alunos e funcionários ao som da canção "School Out" do cantor Alice Cooper. No entanto, antes de se iniciar esta destruição vemos um diálogo de Bart com a professora. Neste diálogo, Bart pede para que ela aumente suas notas, sem nenhuma justificativa pedagógica para tal. Além de aumentar as notas de Bart, ao final do diálogo a docente ainda afirma que irá sentir falta do garoto. Ao consideramos que é um sonho pertencente a Bart notamos uma profunda ambiguidade, pois o aluno parece desejar, simultaneamente, ver a destruição da escola e que a professora aumente suas notas e sinta sua falta. Pois, ao mesmo tempo que o sonho pode retratar uma repulsa à escola devido a destruição que vemos ocorrer ao fim da cena, o garoto deseja fazer parte da lógica escolar, recebendo boas notas e o afeto da professora. De certa forma, podemos observar uma tensão entre um desejo de destruição da instituição escolar, e um desejo de pertencer a sua lógica, recebendo boas notas e o carinho da docente. $\mathrm{O}$ afrouxamento da tensão existente neste contexto social é retratado ao vislumbramos os personagens de alunos e profissionais escolares destruindo o prédio da instituição escolar com amplos sorrisos em seus rostos.

A ambiguidade e a tensão são elementos integrantes dos processos sociais, segundo Bhabha (1998). O estudioso afirma que as contradições e ambivalências constituem a estrutura da subjetividade dos seres humanos. De modo a defender que os termos de antagonismo e afiliação dentro de disputas de poder são desenvolvidos performaticamente e longe de ser estáticos, possuem uma grande possibilidade de flutuação e de deslocamentos. No contexto escolar no qual os jovens ainda se encontram em formação podemos notar grande flutuação nas posições sociais por eles ocupadas, no entanto, irão existir alguns processos que poderão atrelar certas identidades a certos sujeitos sociais. Sendo que seu espectro de ações possíveis e esperadas dentro da instituição escolar não será apenas condicionado por estes processos de identificação, mas também pela forma como estes estudantes são vistos por colegas e profissionais escolares.

Estas classificações e suas relações com as concepções de futuro que os estudantes têm de si e que os demais atores escolares possuem sobre eles, foi objeto de um outro escrito

${ }^{1}$ A cena pode ser assistida em: https://www.youtube.com/watch?v=45IXc-_7kww (Acesso em 23/01/2020) 
(MONTEIRO, 2019), e o objeto central da pesquisa da qual os dados empíricos aqui utilizados advêm. Ao realizar um projeto de pesquisa que envolvia uma tentativa de compreender as relações entre as condutas adotadas por estudantes do ensino básico na escola e o futuro por eles e a eles projetado, me deparei constantemente com questões que envolviam a disciplina escolar. Pude constatar o argumento de Rodrigues (2007) de que as escolas, enquanto instituições disciplinares mediam suas relações através de uma lógica disciplinar. Sendo também, a indisciplina escolar algo frequente, como pude observar. A indisciplina comumente lida como algo oposto à lógica disciplinar, não pode se apresentar sem a existência da disciplina. Optei, portanto, por designar a lógica observada através da seguinte grafia: (in)disciplina. Pois, haveria uma divisão não-estanque entre estas duas lógicas, assim como, uma extrema ambiguidade. De modo que apenas poderíamos classificar uma a partir da outra. O escopo deste trabalho é o de refletir sobre esta lógica, intentando traçar uma linha de inteligibilidade que nos permita compreender como acontece a micropolítica da escola no que tange a lógica (in)disciplina. A visibilidade como elemento da micropolítica existente na escola será o fio condutor da análise proposta. De modo que, a partir da vinculação da visibilidade à reflexão acerca da (in)disciplina escolar, intenta-se compreender como comportamentos lidos como indisciplinados, que muitas vezes são classificados como contrário a lógica escolar, ou a escola, enquanto instituição, são na verdade parte de constantes atualizações que permitem a escola se conservar. Dentro de um arcabouço teórico composto por Deleuze e Guattari (2012) estes comportamentos lidos como indisciplinados poderiam ser encarados como linhas de segmentação molecular, efeitos de uma micropolítica vivenciadas nas relações cotidianas que interfere e interage com instituição sociais consolidadas como a escola, no vocabulário destes autores os elementos institucionais da escola, como a legislação que prevê uma certa padronização das instituições deste tipo, bem como, delimita diversas ações que cabem, ou não, a serem realizadas no ambiente, são linhas molares que constituem o ambiente e vivem uma relação dinâmica, e por vezes conflituosas, com os micro-movimentos das linhas moleculares. Provocando, desta forma, micro-movimentos que quando realizados sob a égide da lógica da (in)disciplina escolar, revitalizam a instituição, de certo modo.

\section{METODOLOGIA}

A metodologia utilizada para a coleta de dados empíricos nesta pesquisa se baseou em uma pesquisa de campo com intenções etnográficas, a qual durou aproximadamente cinco meses. No fim deste período de campo foram realizadas entrevistas semiestruturadas com alunos dos três anos do ensino médio. As entrevistas funcionaram como forma de aprofundar a compreensão de observações realizadas, estas foram gravadas em áudio e depois transcritas. Os alunos entrevistados foram encaminhados pela inspetora da escola, já sendo rotulados por ela como 'bons alunos', 'maus alunos', ou alunos 'medianos' em relação a disciplina escolar. Outra forma de seleção dos alunos, consistiu em entrevistar alunos que possuíam fichas na sala da mediação, nas quais eram registradas descrições de atos lidos como indisciplinados perpetrados pelos estudantes. Nos parágrafos subsequentes situo meu posicionamento metodológico.

A mais famosa definição sobre a etnografia, talvez, tenha sido popularizada por Geertz (1981) ao defini-la como uma descrição densa. A utilização desta ferramenta metodológica permite uma mirada a partir de um viés interpretativo, acima de tudo. Pois, o terreno da cultura, se constrói como um local onde as ações sociais possuem intrínsecas a si um significado simbólico. Desta maneira se busca a interpretação da ação social corporificada e não do comportamento individual. Se realiza uma espécie de diagnóstico post facto. "O objetivo é tirar grandes conclusões a partir de 
fatos pequenos, mas densamente entrelaçados, apoiar amplas afirmativas sobre o papel da cultura na vida coletiva”. (GEERTZ, 2008, p. 38). Goldman (2003), argumenta que uma teoria etnográfica deve ter como objetivo elaborar um modelo de compreensão de um fenômeno social, que mesmo que seja produzido em e para contextos particulares, forneça uma matriz de inteligibilidade que funcione em contextos diversos. Para este autor, se trata de deixar a realização de questões abstratas para dirigir o foco do pensamento para o modo como ocorrem os funcionamentos e as práticas da realidade estudada. Para isto, o pesquisador deve se deixar afetar por aquilo que afeta o "nativo", esta afirmação quando transportada para o estudo de sociedades complexas, implica que o estudioso deve perceber e se deixar levar por uma afecção, não ao que o inflige como ser vivente, mas por aquilo que afeta as pessoas com quem realiza a sua pesquisa. Quirós (2014), traz à baila que a etnografia é uma apreensão de processos desenvolvidos por seres viventes, por um outro ser vivente, de modo que ambos constituem suas sociabilidades naquele espaço a partir de interações desenvolvidas naquele ambiente. Não apenas as "palavras ditas" em resposta às perguntas do pesquisador, principalmente nas entrevistas em profundidade, devem ser consideradas como um dado empírico. A atenção direcionada a mensagens não-discursivas, ao que as pessoas dizem entre elas, ou mesmo aos desabafos realizados pelos sujeitos, podem e devem ser considerados tão importantes quanto as respostas as questões diretas do pesquisador. Elementos centrais à perspectiva etnográfica adotada, que visa apreender ações sociais corporificadas, foram apresentados. Esta se constitui como uma descrição densa, na qual o pesquisador se deixa afetar, por aquilo que afeta os sujeitos sociais imersos no ambiente estudado, bem como, intenta capturar no ambiente, em conversas escutadas, em palavras não-ditas, em certas hesitações e em toda a dinâmica social que ultrapassa as entrevistas semiestruturadas, evidências que permita com que se capte a densidade das relações sociais presentes naquele espaço.

\section{INDISCIPLINA: TRÊS MARCOS TEÓRICOS/TEMPORAIS}

A temática da indisciplina escolar emerge no Brasil como objeto de estudo no contexto da redemocratização. Os estudos pioneiros sobre a temática da indisciplina escolar não distanciavam indisciplina e violências realizadas na escola e contra a escola. (GUIMARÃES, 1984; MOURA, 1988). Os anos 1990 trazem segundo Silva (1998) uma produção que trata a indisciplina escolar de forma transversal, ou vicária, em geral, como um fragmento observado dentro de um universo maior. Tanto Sposito (2001), quanto Zechi (2008) asseveram que neste mesmo período há uma falsa impressão de que indisciplina e violência seriam problemas encarados apenas por escolas de periferia de grandes cidades. Falsa impressão alimentada também no início da década de 2000 devido ao recorte das escolas observadas. Esta mesma década marca a proliferação de trabalhos de campo realizados dentro de escolas e que visavam compreender questões ligadas à indisciplina escolar in loco. Um primeiro marco teórico importante de sinalizarmos pode ser considerado fruto de uma coletânea organizada por Aquino (1996), amplamente citada nestes trabalhos. Nesta coletânea existe uma ênfase na violência perpetrada pela instituição escolar no processo de disciplinar e inculcar conhecimentos nos alunos (ZECHI, 2008; SPOSITO, 2001). Ou seja, neste primeiro momento se concebe a indisciplina escolar, como próxima, por vezes sinônimo da violência na escola, e contra a escola. Bem como, se pautam as reflexões teóricas em um viés que identifica a escola como perpetradora de uma violência primeva.

Um segundo marco que podemos assinalar reflete um descompasso entre as percepções de professores do ensino básico e as produções acadêmicas. Enquanto os professores se sentem desmotivados (BUFFA, 2014), concebem a indisciplina escolar como um entrave pedagógico, algo 
que não os permite ministrar suas aulas (FERREIRA et. al., 2016) e elencam outros atores, que não eles, como responsáveis por essa configuração extremamente estressante que a sala de aula assumiu hodiernamente. Por um outro lado, diversos estudiosos da educação conceberam, até meados dos anos 2010, trabalhavam dentro de uma ordem discursiva que concebia a indisciplina como resistência (ZECHI, 2008; GROSS, 2009; MENDES, 2009; HAVENSTEIN, 2009; FONSECA, 2009), e não raro, dedicando elogios a práticas indisciplinares estudantis, a maioria destes estudos se pautava em estudos de campo. Knöpker (2014; 2015) afirma que os discursos da academia, não raro, alavancavam a disciplina escolar como um "bicho-papão" que impediria a elaboração de um modelo educacional voltada à libertação dos sujeitos. Nota-se, deste modo, um certo esgotamento das produções que elencavam a escola como perpetradora de uma violência disciplinadora que gerava como espécie de efeito rebote a indisciplina escolar.

Durante a segunda metade da década de 2010 podemos considerar consolidação de um novo marco teórico, no qual outros conceitos que não o de resistência ganham força nas ponderações de pesquisadores da indisciplina no Brasil. Estes pesquisadores irão basear suas concepções em diversos outros autores, além de Michel Foucault, e diversificar a produção sobre a temática. Castro e Rodrigues (2016) sugerem a análise de questões indisciplinares através do conceito de concentração dispersa de Türcke (2010); Martins et al. (2016) focam sua análise na dimensão da mediação de conflitos; Alves (2016) discute acerca da construção de uma percepção midiática do tema, e que não coaduna com o retratado pelas pesquisas realizadas; Matos e Ferrão (2016) analisam a relação entre indisciplinar escolar e repetência; Schilling e Angelucci (2016) e Botler (2016) cada qual a seu modo levantam o conceito de justiça como motor analítico à questão da indisciplina escolar; Silva Neto e Barretto (2018) discutem possibilidades de construção de ordem no espaço escolar; Moura e Prodócimo (2019), por sua vez, intentam compreender os mecanismo de contenção da indisciplina escolar e porque estes não logram êxito; Gonçalves (2018) e Silveira (2021) se baseiam, cada um a seu modo, no conceito de inventividade; Silva Neto (2019), parte de uma visão de gênero, principalmente baseado no conceito de masculinidades para realizar sua análise; ao passo que Pereira (2019) investiga a partir de uma clivagem de gênero as diferenças na indisciplina escolar de meninos e meninas; Doirado (2020) trabalha em uma perspectiva crítica em relação a medicalização da educação e dos comportamentos lidos como indisciplinados; Ferreira (2019) se vale do conceito de resistência em sua pesquisa, mas de modo diferente, pois através do conceito de minorias ativas questiona a pretensa anomia do ambiente escolar; e Marchetti (2019) realiza uma pesquisa baseada na análise do discurso como método e que se debruça sobre a omissão da violência perpetrada pela instituição nos discursos de alunos, profissionais escolares e responsáveis legais dos discentes, assim como, nas constantes reafirmações de impotência da escola frente a indisciplina escolar.

\section{INDISCIPLINAR É RESISTIR?}

$\mathrm{Na}$ obra de Foucault encontramos que poder é verbo, é relação, não possui um detentor, e é algo que produz agenciamentos determinados historicamente. Deleuze e Guattari (2012), assinalam que na analítica foucaultiana as relações e os dispositivos de poder possuem dois polos, um de normalização e outro de resistência. Para o próprio Foucault (1988), além de móveis e transitórias:

[...] (as relações de poder) não podem existir senão em função de uma multiplicidade de pontos de resistência que representam nas relações de poder, o papel de adversário, de alvo, de apoio de saliência que permite apreensão. Esses 
pontos de resistência estão presentes em toda a rede de poder. Portanto, não existe, com respeito ao poder um lugar da grande recusa (...). Mas sim resistências no plural, que são casos únicos (FOUCAULT, 1988, p. 91) [Grifado no original].

Dentro desta analítica, a normalização geraria a sua própria antítese, a resistência. Alocar os comportamentos dos estudantes que fugissem ao que uma normalização escolar esperasse como resistência, permite um certo caminho de compreensão, e possibilita alçar elementos para uma reflexão sobre a(s) lógica(s) da indisciplina escolar no ambiente escolar no qual o campo se desenvolveu. No entanto, esta maneira de analisar o mundo escolar não parece compreender a complexidade do mundo escolar, pois elege a instituição social como uma espécie de 'monstruosidade' normalizadora e os alunos indisciplinados como um tipo de seres humanos louváveis por sua resistência. A realidade social é mais complexa que isto.

Nos debruçaremos, brevemente, sobre um trabalho que analisa a indisciplina escolar. Intento neste trecho separar elementos que serão relevantes à análise empreendida aqui e outros os quais podem ser armadilhas para uma compreensão do fenômeno. Cabe salientar que a corrente de pensamento que possui em Foucault e Deleuze dois de seus mais influentes autores não analisa os eventos sociais em uma relação puramente ascendente na qual, alguns exerceriam o poder e outros apenas seriam formatados por ele.

Uma relação simplista de que alunos são indisciplinados porque a escola intenta os disciplinar, sufoca a potencialidade analítica das relações presentes neste ambiente. Ao ler o artigo de Dinali e Ferrari (2011) podemos perceber um exemplo disto. Este excerto do texto, que se localiza após os autores descreverem uma série de reclamações realizadas por um aluno, após ser expulso da sala de aula pela professora, nos fornece alguns elementos à reflexão:

É possível observar como o comportamento do aluno, que foi tomado
"indisciplinar", diz respeito a uma reação contra esse modelo de escola
disciplinar, uma negação a esses efeitos de poder. O aluno, ou melhor, sua çãa,
aponta para outras relações, para outros espaços possíveis. "Ignorando" isso, a
professora agiu sobre a lógica disciplinar, lançando fora a potencialidade que
esses jogos de forças podem sugerir, podem provocar. É interessante perceber
que a professora age respeitando sua formação, sua concepção de escola e
educação, as normas da escola, enfim, é possível refletir como as relações de
poder constituem essa professora e a impossibilitam de ver a reação e a relação
com os alunos sob outra perspectiva. Podemos notar que além de apontar para
processos de transformação, as resistências são lutas sociais, minúsculas, que
negam as formas de exercício de sujeição. Que elas se dão não contra o poder,
mas contra certos efeitos sobre os corpos. (DINALI e FERRARI, 2011, p. 472-
473).

Dois apontamentos se fazem necessários sobre estas afirmações, o foco nas resistências dos alunos enquanto algo positivo, como realizado pelos autores, aloca, talvez sem que estes se deem conta, os profissionais escolares como uma espécie de vilões que tentam disciplinar os alunos que heroicamente lutam contra seu jugo. Em segundo lugar, a última frase do excerto mostra qual a exata dimensão que sua análise capturou, a ação contraria a certos efeitos sobre os corpos de determinados estudantes. Entretanto, posteriormente irão alocar a existência de resistência como um fato que proporciona prazer a quem resiste ao poder, algo verificado empiricamente, mas que possui contorno diferente do apresentado por estes autores.

Os argumentos a que este paper se propõe tendem a considerar o microcosmo escolar como algo mais complexo, assim como, a questão da (in)disciplina, sem desconsiderar as relações existentes entre normalização/resistência e espirais de prazer/poder. No entanto, irei argumentar 
que apenas este viés não permite uma compreensão apurada da lógica presente na instituição e devemos observar as consequências destes atos lidos como indisciplinados, antes mesmos de o serem classificados como tais. De modo que o argumento estrutural deste paper é que os alunos realizam atos considerados de indisciplina por diversos motivos, dentre estes enfoco na questão da visibilidade proporcionada por tais ações, ou então, uma busca de se tornar visível no espaço escolar que é lida como indisciplina. Argumentarei que estes atos rotulados de indisciplinares realizam micro-rupturas na lógica disciplinar da escola, mas os alunos ao perpetrar atos lidos como de indisciplina, realizam um reforço desta lógica e não sua negação. Ou seja, não são contrários ao ambiente escolar, mas parte constituinte e necessária deste.

\section{A INDISCIPLINA COMO CONFLITO: RELAÇÕES ENTRE PRAZER E PODER}

Atos lidos como indisciplina repercutem no ambiente escolar não como uma resistência a sua lógica, mas como momentos que entregam aos alunos visibilidade. Nesta seção refletiremos sobre o que enseja momentos de conflito entre profissionais escolares e alunos. Não raro após estes conflitos algumas atitudes realizadas pelos alunos são consideradas como de indisciplina. Existe na escola um ideário de que os alunos precisam ser extremamente disciplinados para que o trabalho docente flua tranquilamente. A escuta de uma conversa entre duas professoras ao comparar lecionar na Fundação Casa e na escola Úrsula Iguarán ${ }^{2}$, nos fornece interessante exemplo. $\mathrm{Na}$ conversa em questão, uma professora comenta que trabalha com menores infratores na Fundação Casa. Uma outra professora a inquere sobre se ela não possuía 'medo'. Uma terceira docente as interpela e comenta que nestas instituições em toda aula há um guarda na sala de aula e que os alunos não fariam 'bagunça', o que é confirmado pela primeira professora. Esta primeira docente afirma que, além de não ter medo, "lá" o trabalho de docente seria mais fácil, pois os alunos se comportavam bem, de acordo com a professora, devido, não apenas a presença de um 'guarda', mas também em função das punições que estes adolescentes receberiam caso demonstrassem um 'mau' comportamento em sala de aula. Encerra o assunto dizendo que 'lá' - na Fundação Casa - poderia exercer sua função 'em paz'.

Os professores brasileiros, hoje, se encontram em sua grande maioria perdidos e exaustos ao ministrar aulas (BUFFA, 2014). Face a esta exaustão é fácil imaginar que estes professores desejem um retorno à uma escola na qual os alunos temiam tremendamente a autoridade docente e, ao menos em seu imaginário, o trabalho docente seria mais fácil e recompensador (FERREIRA et al., 2016). Os profissionais escolares são peça fundamental à lógica (in)disciplina vislumbrada no ambiente escolar, pois são eles que, em geral, classificam se tal ato foi de indisciplina ou não, eles que podem se valer de mecanismos burocráticos para tentar coibir certos atos, ou seja, na maior parte do tempo os profissionais escolares devem exercer a função de disciplinar. A etnografia me revelou que os atos indisciplinados são classificados a posteriori pelos profissionais escolares, ou seja, apenas se torna um ato de indisciplina ao ser lido assim por um profissional escolar. Não há consenso entre os profissionais escolares, sendo que esta classificação ocorre de forma situacional. Dentro deste contexto se faz difícil atrelar indisciplina escolar a resistência.

Durante as entrevistas, por vezes, tive acesso a fichas dos alunos, nas quais estavam anotados atos lidos como de indisciplina e que os levaram à direção ou a sala da mediação. Ao entrevistar Eduardo, este aluno após tecer críticas às profissionais que haviam anotado suas atitudes indisciplinadas, me contou sobre um acontecimento que não estava presente em suas fichas. Ele

\footnotetext{
2 O nome da instituição e dos alunos são fictícios, a fim de cumprir com um acordo de confidencialidade. Os profissionais escolares são indicados de acordo com a função exercida no ambiente escolar.
} 
fora expulso da sala de aula ao realizar uma selfie com o celular. Na conversa com o Diretor, segundo o estudante, este o compreendeu sem o repreender e disse para aguardar o sinal sonoro que sinaliza a troca de aula para retornar para sua sala. O aluno traz este relato como um contraponto as formas como outras profissionais escolares tratavam seus atos lidos como de indisciplina. Podemos retirar duas ponderações deste relato: a primeira é de que nem sempre o ato de um estudante lido como de indisciplina por um profissional escolar o será por outro. A segunda ponderação nos remete a Türcke (2010). A compulsão por emitir e por estar presente no mundo digital não se encerra nem quando os estudantes estão em sala de aula. Podemos especular, ao menos, duas razões para a selfie de Eduardo a necessidade de aparecer no mundo virtual durante o período de aula, mostrando ser destemido ao realizar uma selfie em sala. Ou, então, a necessidade de Eduardo de aparecer à sala ao realizar uma selfie, de modo a ser visto como um aluno potencialmente 'descolado'. Em ambos os cenários especulados é necessário ao aluno emitir, ser visto, aparecer, isto indubitavelmente lhe seria fonte de prazer, pois ao desobedecer a professora e se manter no celular Eduardo emitia e se fazia presente tanto no mundo digital, quanto assinalava sua presença no espaço físico da sala de aula. De modo que Eduardo se fazia visível, logo, percebido em dois planos simultaneamente, pois ele emitia no mundo digital a sua selfie, ao mesmo tempo, em que se mostrava destemido a seus colegas.

Os alunos e as condutas alocadas sobre a pecha de indisciplinares não são apenas vistos, mas também comentados, reverberam no ambiente escolar. $\mathrm{O}$ assunto preponderante da sala dos professores é rotineiramente o comportamento dos alunos, principalmente os comportamentos lidos como indisciplinados. Certo dia, pude observar uma professora contar a mesma história umas três, quatro vezes a diferentes colegas. A professora relatava um jogo de força realizado entre ela e um aluno na porta da sala. O aluno recusava manter-se no espaço de sala de aula constantemente se projetando para fora desta, pois o intervalo se aproximava. Provavelmente o aluno se localizava no extremo da sala, rente à risca que marca a fronteira entre a sala de aula e o corredor, como pude observar diferentes estudantes fazerem, em diversas oportunidades. A professora então resolve fechar a porta, de modo a manter o aluno dentro da sala, o aluno tenta a impedir. Neste momento há uma disputa de força física entre os dois, a docente consegue fechar a porta e impedir que o estudante deixe a sala. O aluno se afasta da porta, reclama de dor no braço e nas palavras da professora: "ficava me chamando de "vagabunda". Os professores para os quais a história era direcionada, concordavam com a professora que o aluno em questão realmente era um 'folgado' e que ela não podia deixar barato. $\mathrm{O}$ tom de voz da professora transmitia orgulho e indignação. Afinal, ela havia ganho o jogo de força, mas considerava o fato de existir um jogo de força física, entre ela e um aluno, algo ultrajante.

Ambos os atores escolares colocados como antagônicos ao descrevermos atos considerados de indisciplina revelam seu prazer seja em disciplinar, seja em ser indisciplinado nestes momentos. As questões que envolvem o prazer em resistir/exercer o poder não podem de forma alguma serem desprezadas, apesar de não explicarem de forma final as questões que mobilizam as reflexões, fazem parte do quadro analítico relevante. Foucault (1988) aponta a existência de perpétuas espirais de poder e prazer - apesar de seu objeto de estudo ser diferente, o filósofo investigava os dispositivos de poder que recaíram sobre a sexualidade e os corpos na Modernidade existem diversas semelhanças nestas configurações que envolvem situações de conflito, relações de poder e embates entre forças. A partir da constituição de um certo regime de interdição de comportamentos e corporalidades o poder penetraria nos ínfimos traços da vida social. As interdições, na análise empreendida por Foucault (1988) e na observação empírica sobre a qual se ancora as reflexões aqui presentes, gerariam algo diferente daquela situação que seria idealizada por alguns, na qual os seres humanos adotariam apenas condutas e ações prescritas e não exerceriam 
práticas não-prescritas, ou desviantes, sem ter como acompanhantes os sentimentos de culpa e vergonha. As interações de seres humanos no e com o mundo não seguiriam, necessariamente, esta premissa, haveria um duplo movimento de prazer e poder que poderia ser observado nestas relações. As sensações de prazer/poder de quem vigia em perceber comportamentos desviantes, intervir e alertar sobre eles, e estas mesmas sensações naquele que está na condição de 'vigiado' em esconder e/ou perpetrar tais comportamentos. Ou seja, na escola os papeis/performances sociais dos profissionais escolares e de alunos indisciplinados permitiriam que estes seres humanos experienciassem sensações de prazer/poder.

Riscos imaginários no chão são objetos de disputas e tensões, seja quando traçam fronteiras entre territórios de Estados, ou quando delineiam a fronteira na escola entre o controle do professor e o não-controle deste. Pude observar constantemente em campo alunos que esgueiravam suas cabeças fora da sala de aula para observar o corredor ou gritar algo para algum colega que fazia o mesmo em outra sala de aula. Ouvi algumas vezes, em outras pude apenas inferir pela resposta do aluno que o professor que estava em sua sala o havia mandado entrar. A resposta dos alunos parecia padronizada, respondiam: "estou dentro da sala" e, por vezes, apontavam para seus pés anteriores a linha como forma de provar. Podemos afirmar que esta é uma atitude normalizada, desde que os pés dos alunos se mantenham dentro da sala os professores não sentem que estão perdendo o jogo de poder, quando alguns destes alunos ultrapassam esta fronteira os professores avançam sobre eles e tentam energeticamente através de gestos e gritos fazer com que entrem. Após a instauração desta disputa um lado sairá vencedor, e contente, e o outro lado amargará uma derrota. Um comportamento interdito como o cruzar uma linha, que se torna objeto de uma disputa traz consigo a exata dimensão de prazer presentes nas análises foucaultianas. Os alunos que sentiriam vergonha ou culpa de realizar tal ato, em geral, não se encontram rente à risca da porta, um professor que permita que seus alunos saiam antes do sinal sonoro poderá ser repreendido pelos gestores escolares ou perder legitimidade frente aos estudantes, os alunos que conseguem subjugar o professor e sair para o intervalo mais cedo poderão se gabar disto. A própria lógica presente na instituição escolar fornece os elementos para que esta disputa sobre uma risca seja importante. De modo a recompensar seus vencedores. O sentimento de orgulho da Professora no caso descrito acima demonstra isto, por mais que considerasse degradante ter que medir força com um aluno sobre o posicionamento dentro ou fora de uma risca, ela havia o vencido. Ela era uma professora que conseguia manter a ordem e o controle da sala de aula.

Estes dois momentos etnográficos revelam a preocupação dos atores escolares com a sua visibilidade. O aluno que fazia uma selfie, a considerava inofensiva do ponto de vista disciplinar, ao menos começou a pensar assim depois da conversa com o diretor. A professora que narrou seu embate com o aluno, de forma ambígua parecia se posicionar como símbolo de resistência docente ao avanço da indisciplina estudantil, considerada em certa medida ultrajante. Em ambos os casos, o que está em jogo era a forma como estas pessoas eram vistas pelos seus pares. A possibilidade de serem vistos de forma positiva pelos pares, parecia gerar prazer nestes atores escolares, seja no momento de disciplinar os estudantes, ou de se fotografar em plena sala, no meio de uma aula. Ao pensarmos que as relações desenvolvidas no ambiente escolar correspondem a interação de linhas molares e moleculares (DELEUZE e GUATTARI, 2012), podemos inferir que são estas dinâmicas conflituosas permitem uma reatualização constante da instituição escolar, pois a cada micro-ruptura na ordem estabelecida, ocorre um micro-movimento, um micro-deslizamento, que desembocam em uma micro-reconfiguração. Um jogo de forças que ora pende à disciplina, ora à indisciplina, mas se encontrássemos uma escola que não o possuísse esta seria irreconhecível, aos padrões, que apesar de desgastados ainda são predominantes quando imaginamos uma instituição escolar. De 
forma que esta lógica (in)disciplina é tão importante, quanto, como por exemplo o ensino, ou a aprendizagem de certos conteúdos, dentre outras dinâmicas e relações presentes na escola.

\section{INDISCIPLINO, LOGO SOU VISTO!}

Como percebemos com Eduardo uma ação para ser considerada de indisciplina precisa ser rotulada como tal pelos profissionais escolares, seja com uma bronca, com o seu registro em uma ficha, ou então com uma sanção administrativa como uma advertência, ou uma suspensão. Pude perceber em diversas oportunidades que apesar de os alunos inferirem comportamentos potencialmente classificados como indisciplinados, este rótulo sempre aparecia como uma classificação a posteriori. Nenhum aluno, mesmo aqueles que me contavam casos de indisciplina que não estavam em suas fichas, afirmou que planejara um ato para que este fosse considerado de indisciplina, as motivações sempre eram outras. Em outras palavras, a indisciplina precisa ser vista e classificada como tal para existir. Foucault (1987) já havia percebido a importância dos olhares, sobretudo os hierarquizados, à manutenção da disciplina em diversos ambientes. Contudo, no ambiente escolar a dinâmica de olhares que localizam e classificam alguma ação como indisciplina, promove certa visibilidade aos alunos indisciplinados. Visibilidade que parece atrair colegas, que por vezes imitam atos de indisciplina (MONTEIRO, 2020), bem como, atraem pesquisadores que se debruçaram sobre o tema e enfocaram suas análises acerca da temática sobre os estudantes, como vimos acima.

Todavia, foram as entrevistas com alunos, principalmente, aqueles classificados pelos profissionais escolares como 'bons', ou comportados, que permitiu perceber que na escola Úrsula haveria um jogo entre o ver e o ser visto (BHABHA, 1998). Este jogo remeteria às espirais de poder $\mathrm{e}$ prazer assinaladas por Foucault (1988). A particularidade no ambiente escolar seria que este jogo de ver/ser visto ocorreria em um ambiente em processo paulatino de desinstitucionalização (DUBET, 1998), no qual diversas moralidades diversas à moral escolar ganham relevância. Sendo que a escola hoje se situa em um contexto social no qual ser é ser percebido (TÜRCKE, 2010), ser visto. Uma das principais características desta configuração histórica seria a necessidade de fazer propaganda de si, para ser notado, percebido, visto, e, portanto, desta forma ser. A propaganda compõe uma nova cultura comunicativa. Desta forma, propagandear a si mesmo se torna necessário à própria auto-conservação, pois "apenas o que causa uma sensação é percebido" (TÜRCKE, 2010: 20) de modo que todos são forçados a se tornarem emissores. Neste momento cabe a questão, os comportamentos lidos como indisciplinados seriam uma forma que os alunos encontrariam de serem percebidos, serem vistos? Rodrigues (2007) possui em sua tese de doutoramento uma interessante provocação. A pesquisadora inquere o leitor se os processos identificados como indisciplina na escola não seriam na verdade, facetas de um processo de autodisciplinamento dispendido pelos seres humanos para sua auto-conservação após a consolidação de um padrão social como o sintetizado por Türcke (2010) na afirmação de que hoje ser é ser percebido. Ou seja, alguns estudantes se construiriam frente a este ambiente escolar visando se fazer presente no espaço de alguma forma, possibilitando a existência de um auto-disciplinamento de alguns jovens em relação a perpetração de atos que imaginam que serão classificados como de indisciplina e os possibilitará serem vistos pelos outros estudantes, os possibilitará destaque.

A visibilidade que os alunos recebem ao perpetrar atos considerados indisciplinados, por vezes, os proporciona um certo prestígio social e o papel de empreendedor moral dentro do espaço escolar (MONTEIRO, 2020). De modo que, propagandear a si mesmo possibilita que os alunos além de serem vistos, possuam também uma certa relevância dentro do ambiente escolar. A aluna 
Hanekawa quando perguntada se notava uma maneira diferente de os profissionais da escola lidarem com alunos 'comportados' e com alunos 'bagunceiros' responde:

Quem é bagunceiro costuma chamar mais a atenção. Quem é comportado já é mais... já é um pouco mais esquecido. Mas, também eles percebem e a nota é maior do que a dos que bagunçam.

Os alunos bagunceiros são lembrados, vistos e percebidos pelos profissionais escolares e pelos seus pares. Esta visibilidade pode se corporificar em relevância. Relevância que, não raro, se traduz em vantagens em situações de conflito, ou vantagens em relação a posição hierárquica que determinado estudante ocupa entre seus pares. Melhores notas/comportamento disciplinado e prestígio social não andam de mãos dadas. Este certo prestígio social alcançado por estes alunos nas relações hierárquicas extremamente precárias entre os pares não sinaliza que os estudantes não possuam toda uma série de conflitos dentro de suas relações sociais. O aluno Danilo, que estava em seu último ano de escolarização quando questionado sobre os pontos positivos da escola Úrsula concentrou sua resposta nas relações interpessoais, pois o melhor da escola seria o fato de que "tem bastante colega pra trocar ideia", ao passo que a parte negativa da escola seria "[...] ter muita gente folgada 'memo', né? Ter que saber lidar com os caras, senão 'os cara' vem pra cima.” A partir das falas de Danilo fica claro as tensões e conflitos existentes dentre os estudantes, conflitos que muitas das vezes podem envolver o ser percebido, visto e ganhar relevância a partir da subjugação de outros alunos, o que pode acontecer pela força física ou através de costumeiras humilhações verbais. Estas tentativas de subjugação do outro seriam atos cometidas por 'gente folgada".

Além disto, diversas entrevistas com alunos que se consideravam disciplinados - assim como, a realizada com Rita - revelaram que estes esperam que as regras escolares incidissem fortemente sobre os comportamentos potencialmente indisciplinados, a fim de os controlar, e potencialmente, os inibir. A aluna Rita relatou acontecimentos nos quais a indisciplina de alguns alunos provocou a desistência da realização de um show de talentos, e outros episódios que levarão a proibição por parte dos gestores do acesso dos alunos a um espaço semelhante a um jardim, até mesmo com a supervisão de professores. Estes seriam exemplos para a aluna que justificariam um aumento da disciplina, como espécie de estratégia preventiva à indisciplina. Contudo, os exemplos da aluna levam-nos a perceber que comportamentos lidos como indisciplinados, que permitem com que alunos sejam vistos e notados criam fissuras na organização da escola, enquanto instituição disciplinar. De modo que estes desterritorializam e criam reterritorializações no espaço escolar.

\section{MOVIMENTO, DESLOCAMENTO E (RE)TERRITORIALIZAÇÃO DA DINÂMICA SOCIAL ESCOLAR SOB A LÓGICA (IN)DISCIPLINA}

Narrar apenas embates entre processos de normalização e resistência não nos permitiria vislumbrar as diversas ambiguidades intrínsecas à lógica (in)disciplina no espaço escolar. Para Bhabha (1998), as articulações e traduções culturais aconteceriam em um espaço ambíguo e contraditório. Argumento que o espaço escolar se encontra permeado destas articulações e de sistemas sociais ambíguos e contraditórios. No qual, são operados micro-movimentos, microrupturas, desterritorializações e (re)territorializações. Os atos considerados como atos de indisciplina revelariam, (re)atualizações constantes da lógica (in)disciplina escolar. Uma lógica social que demonstra articulações da lógica escolar com lógicas exógenas a instituição.

\footnotetext{
${ }^{3}$ Fora interessante notar que em geral tudo aquilo que se costuma chamar de bullying é sintetizado por grande parte dos alunos da escola estudada como obra de folgados, ou de gente folgada.
} 
Podemos considerar o espaço escolar como espaço no qual o ocorrem constantes territorializações, desterritorializações e reterritorializações. O aluno Pedro Paulo em conversa informal, me relatou que ao chegar na sala de aula após ser entrevistado, foi cercado pelos outros alunos que o inquiriam sobre o que se tratava a entrevista que fora realizada com ele. Pedro Paulo, conta que os estudantes haviam parado de se prestar atenção no professor, para prestar atenção no seu relato sobre a entrevista, o que fez com que Pedro Paulo "se sentisse o professor". As ambiguidades presentes neste curto relato, me fazem pensar o quanto para além de resistência a um processo normalizador se encontram os estudantes que não obedecem piamente às regras da instituição escolar. Pois, apesar de que de certa forma o aluno nega o jogo de poder professoraluno e o ressignifica a uma nova configuração, argumento que esta nova configuração se encontre para além dos polos normalização e resistência. Pois, Pedro Paulo se sentir como o professor por ser o centro das atenções na sala de aula, não nega ou resiste as configurações escolares, as reforça. Entretanto, as reforça de um jeito diferente, ao fazer com que o professor, de fato, deixasse de ser o foco de atenção da sala. Opera um micro-movimento de deslocamento das relações estabelecidas institucionalmente. Ou seja, o aluno desterritorializa as relações estabelecidas em sala de aula, a partir da própria lógica da sala de aula, na qual alunos atentamente escutam as explicações de um professor e as reterritorializa de forma diferente e ambígua. De modo a dar as costas a relação institucional negando o professor, mas ao mesmo tempo reforçando a lógica escolar ao se "sentir como um professor".

A aluna Violeta, uma aluna do segundo ano do ensino médio que fora entrevistada simultaneamente com outros dois alunos, pois os três foram expulsos da sala de aula em conjunto, demonstra todo o caráter ambíguo presente nas tensões do ambiente escolar.

Violeta: Ah, eu quero fazer uma faculdade de pedagogia. Mas tá difícil.

$[\ldots]$

V: Ah, eu pretendo. Eu pretendo, mas é só o básico só. Tem que ter alguma coisa certificado mermo. De coisa, de diploma e tudo. Não pode ser só um curso. Quero fazer mestrado igual você faz.

Entrevistador: Mas na área de pedagogia?

V: Isso. Aí, quero ser diretora da escola (risos ao fundo) e tirar [sarro de] tudo esses pirralhos aqui (risos dela e dos outros).

A afirmação da aluna que desejava se tornar diretora provoca risos em seus colegas, afinal eles estavam sendo entrevistados justamente porque haviam sido expulsos da sala de aula por algum comportamento lido como indisciplinado por sua professora. Violeta não nega a lógica escolar, mas enxerga nela a chance de se realizar enquanto profissional, mesmo de maneira pouco ortodoxa, ao afirmar que seu objetivo era o de poder tirar sarro dos alunos. Podemos afirmar que existem jogos de forças múltiplos que tentam deslocar a lógica escolar, para diversas direções, através das ações de seus sujeitos. No entanto, sejam os alunos considerados mais indisciplinados, ou sejam os profissionais escolares mais rígidos ao provocar tensões movimentam a lógica (in)disciplina e a reforçam constantemente, mesmo que de forma ambígua.

Poderíamos relacionar estes processos nos quais os estudantes deslocam de alguma forma relações institucionalizadas como a corporificação de linhas moleculares (DELEUZE e GUATTARI, 2012) as quais operam micro-movimentos e micro-rupturas. A questão do ser visto, ser percebido, possui centralidade nestas questões, pois os alunos a conferem importância. No caso sucintamente descrito acima, podemos enxergar o aluno Pedro Paulo, reterritorializando as relações de força presentes em sala de aula, o centro de visibilidade deixa de ser o professor, para se tornar o estudante. A visibilidade dos alunos é trazida à baila também diversas vezes. A aluna Rita em sua 
entrevista afirma que para se destacar da massa apática de alunos visualizados pelos profissionais escolares decidiu participar do grêmio estudantil. A aluna Violeta afirmara que desejava o cargo de maior destaque no ambiente escolar, a direção.

Professores também reforçam esta lógica e encaram estes micro-movimentos como, de certo modo, importantes ao desenvolvimento dos discentes. Em conversa entabulada com uma professora readaptada ${ }^{4}$ e entrevista com outra professora, ambas me afirmaram que um 'bom' estudante, com potencial de alcançar um bom-futuro não seria aquele discente que possui posturas classificadas por elas como apáticas, elas localizaram nos discentes, em geral, envolvidos com atos considerados de indisciplina, mas de pequena gravidade, como falar exacerbadamente em sala de aula, alunos com potencial de alcançar "bons-futuros" para si. Pois, este certo grau de rebeldia, os diferenciaria de estudantes, que se comportam bem, mas são pouco vistos, de modo a receber o rotulo de apáticos. Ao enxergar nos estudantes que não são exatamente exemplos de disciplina de forma positiva em relação a uma boa possibilidade de futuro, as profissionais escolares manejam micro-rupturas na estrutura molar da instituição, assim como, demonstram uma ambiguidade e diversidade nos discursos docentes, entre um ideário de alunos extremamente docilizados, como no caso das professoras que conversavam sobre a Fundação Casa, e alunos que apesar de suas indisciplinas demonstram certo potencial.

Contudo, de certo modo, os profissionais escolares, acabam legitimando a indisciplina escolar dos alunos. Fornecem rótulos de aluno-problema a certos alunos, o que os coloca em posição de destaque em relação aos demais. Destaque que torna estes alunos visíveis e ao mesmo tempo os fornece relativo poder, pois serão estes que deslocarão as estruturas existentes na instituição escolar. Não à toa a aluna Rita afirma que para se destacar na instituição escolar, um aluno que não se envolva em atos de indisciplina com frequência, como era o seu caso, deve realizar algo como participar de chapas do grêmio estudantil, pois apenas assim ganhariam certo destaque. Etnograficamente também era notável o carinho que alguns alunos recorrentemente envolvidos em atos de indisciplina recebiam de profissionais escolares, principalmente, aqueles alunos que não cruzavam certos limites em seus atos.

\section{CONSIDERAÇÕES FINAIS}

Este escrito se debruçou acerca das configurações escolares, a fim de traçar uma linha de inteligibilidade que permitisse a compreensão da lógica (in)disciplina escolar, sob a luz da constatação da visibilidade, como algo importante no contexto social hodierno. De modo que, a resistência estudantil aos processos de disciplinamento escolar, responderia, muitas vezes, ao desejo de ser visível no ambiente escolar, e não uma resposta direta aos processos disciplinares perpetrados pela instituição. Consideremos o conceito de linha de fuga, que para Deleuze e Guattari (2012), possuiria equivalência ao conceito foucaultiano de resistência, estas linhas de fuga seriam a desterritorialização absoluta. Sendo que o principal perigo da linha de fuga seria se transformar em uma linha de destruição. Ao pensarmos no ambiente escolar, as rupturas, quando ocorrem, são constantemente reterritorializadas e não permitem uma desterritorialização absoluta. Ou seja, os atos lidos como de indisciplina e os alunos classificados como indisciplinados, longe de

\footnotetext{
${ }^{4}$ Professores readaptados são professores que foram afastados de sala de aula devidos a problemas psicológicos desenvolvidos pelo estresse da profissão. Muitas vezes, ao retornar para a escola não realizam atividades docentes, mas de outro gênero. No caso da professora em questão ela auxiliava os docentes a imprimir e xerocar suas avaliações e atividades a serem desenvolvidas em sala de aula que necessitassem ser impressas. As normas e critérios relativos à readaptação de servidores da Secretaria da Educação de São Paulo encontram-se na Resolução SE 18, de 10/4/2017.
} 
realizar uma desterritorialização da lógica escolar, eles a reforçam, mesmo que durante este reforço a lógica disciplina seja levemente deslocada ou sofra uma micro-ruptura. Argumento que estas práticas dos atores escolares operam no plano que Deleuze e Guattari (2012) classificam como molecular, no qual são operadas diversos micro-movimentos e micro-rupturas. Estas microrupturas, farão com que profissionais escolares a depender da situação encarem certo comportamento como aceitável ou não. Para disciplinar é necessário encontrar atos de indisciplina. Classificar atos como de indisciplina, reforça a ideia de que é necessário disciplina, entretanto, a cada vez que existe confronto estas disposições são atualizadas e rearticuladas de forma microscópica.

Os comportamentos lidos como indisciplinados movimentam a escola, de modo que esta busque a sua conservação. Os exemplos fornecidos pela aluna Rita, demonstram os modos como o comportamento dos alunos pode modificar, inclusive, quais são os espaços permitidos ao acesso dos estudantes no ambiente escolar. Isto denota, que a escola se rearticula a fim de não perder, certo controle sobre os estudantes. Ao mesmo tempo, diversos casos de alunos indisciplinados, como quando Pedro Paulo, se "sentiu o professor" possibilitam observar que há uma grande ambiguidade nos atos considerados de indisciplina, pois, eles não negam a configuração escolar, mas sim mergulhados nela, eles podem a reforçar, mesmo que de maneira dúbia. Sendo que as relações de antagonismo e filiação à escola performadas pelos alunos, possuiriam este caráter ambíguo, constantemente. Ou seja, em geral, os comportamentos considerados de indisciplina dos alunos, canalizam dinâmicas muito diferentes de uma desterritorialização absoluta, que sugere o conceito foucaultiano de resistência. Mas sim, promovem reatualização e micro-movimentos na instituição escolar. Ou então, possuem outros objetivos, como conseguir ser visto.

A compreensão do ambiente escolar passa por não encarar as relações escolares como desenvolvidas apenas nas relações entre professores e alunos. Independentemente de qual leitura epistemológica que se pretenda fazer dos processos escolares. Pois, existem diversas dinâmicas sociais entre pares, sendo entre alunos, ou entre profissionais escolares. Bem como, existe uma hierarquia e certos direcionamentos institucionais, linhas molares, os quais a escola deve responder. Deste modo, não podemos encerrar a compreensão das dinâmicas escolares apenas na realidade local, apesar das diversas pistas fornecidas por ela. Este encerramento local, por exemplo, pode nos fazer transmitir a falsa sensação de que cada instituição escolar é um local no qual profissionais escolares intentam impor uma disciplina e os alunos resistem bravamente a estes processos. Exemplo que intentei desmontar neste escrito com uma pesquisa de caráter local. Todavia, para profissionais escolares - que devem responder as demandas institucionais - o jogo de normalização não se encerra em um versus contra alunos que precisam ser disciplinados. De modo que, quiçá, a legitimação, mesmo que não-intencional, dos atos de indisciplina dos estudantes também seja uma forma destes profissionais de tentar ganhar visibilidade frente a um sistema educacional que os desvaloriza, ou então, de deslocar premissas deste sistema de educação burocratizado que sabem não mais fazer sentido nos dias de hoje. Estas derradeiras inferências têm como objetivo fomentar outras pesquisas na área e não correspondem aos dados empíricos que se focaram em outro fenômeno, no entanto, considero reflexões importantes. 


\section{REFERÊNCIAS}

ALVES, Mariana Gaio. Viver na escola: indisciplina, violência e bullying como desafio educacional In: Cadernos de Pesquisa. v. 46, n. 161, p. 736-754, jul./set. 2016.

AQUINO, Júlio. Groppa. (org.) Indisciplina na escola: alternativas teóricas e práticas. São Paulo: Summus, 1996.

BHABHA, Homi K. O Local da Cultura. Belo Horizonte. Editora da UFMG, 1998.

BOTLER, Alice Miriam Happ. Injustiça, conflito e violência: um estudo de caso em escola pública de Recife. IN: Cadernos de Pesquisa. v. 46, n. 161, p.736-754, jul./set. 2016.

BUFFA, Mauricio. O debate enfraquecido: o desanimo dos educadores diante da realidade cotidiana das escolas. 338f. Tese de Doutorado em Educação, Universidade Federal de São Carlos - UFSCar, São Carlos, 2014.

CASTRO, Camila Sandim de; RODRIGUES, Luciana Azevedo. Disciplina e indisciplina escolar em tempos de sociedade excitada. Impulso, Piracicaba v. 26 n. 67 p. 23-37, set./dez. 2016

DELEUZE, Gilles; GUATTARI, Félix. Mil Platôs: Capitalismo e esquizofrenia. São Paulo: Editora 34, 2012. Vol. 3

DINALI, Wesley; FERRARI, Anderson. "É meu último ano aqui mesmo [...] Tô pensando em botar fogo na escola": o cotidiano escolar e as práticas de resistências. Revista Contemporânea de Educação. n. 12 - agosto/dezembro de 2011.

DOIRADO, Edmilson Fernandes. Discursivização sobre indisciplina e doenças do não se comportar nos anos iniciais do Ensino Fundamental na perspectiva da medicalização da educação. 116 f. Dissertação de Mestrado - Universidade Estadual Paulista, Marília, 2020.

DUBET, François. A formação dos indivíduos: a desinstitucionalização. In: Revista Contemporaneidade e Educação. ano 3, v. 3, 1998, p. 27-33.

FERREIRA, Adriano Charles. Representações sociais dos alunos do $9^{\circ}$ ano com indícios de Minorias Ativas em relação à indisciplina escolar. 248 f. Tese de Doutorado. - Universidade Estadual de Ponta Grossa, Ponta Grossa, 2019.

FERREIRA, Adriano Charles et al. Representação social da indisciplina escolar. Psicologia: Teoria e Pesquisa. v. 32 n. 1, p. 199-208, jan./mar. 2016.

FONSECA, Adriana de Castro Disciplinando o corpo de Alice: maravilha e controle na escola contemporânea, 2009, 101s. Dissertação (Mestrado em Educação). Faculdade de Educação, Universidade Federal de Juiz de Fora, Juiz de Fora.

FOUCAULT, Michel. Vigiar e Punir. Petrópolis: Editora Vozes, 1987.

FOUCAULT, Michel. História da Sexualidade I: A vontade de saber. Rio de Janeiro: Edições Graal, 1988.

GEERTZ, Clifford. Common Sense as a Cultural System In: GEERTZ, Clifford. Local Knowledge: Further Essays In Interpretative Anthropology. Basic Books, Inc. EUA: 1981

GEERTZ, Clifford. Uma descrição densa: Por uma teoria interpretativa da cultura IN: GEERTZ, Clifford. A interpretação das culturas. Rio de Janeiro: LTC, 2008.

GOLDMAN, Marcio. Os tambores dos mortos e os tambores dos vivos. Etnografia, antropologia e política em Ilhéus, Bahia. Revista De Antropologia, São Paulo, USP, 2003, v. 46 n. 2. p. 445 - 476.

GONÇALVES, Vanessa Bugs. Táticas e Estratégias: uma descontrução da noção de indisciplina no cotidiano escolar. 153 f. Tese de Doutorado - Universidade Federal de Pelotas, Pelotas, 2018. 
GROSS, Ivan. Discurso pedagógico sobre indisciplina escolar, 2009, 114s. Dissertação (Mestrado em Educação). Departamento de Educação, Universidade Tuiuti do Paraná, Curitiba.

GUIMARÃES, Áurea M. Vigilância, Punição e Depredação Escolar. Papirus: Campinas, 1988.

HAVENSTEIN, Sharlene Wenz. Letrinha bonita, corpinho quieto e boquinha fechada: um estudo sobre os mecanismos disciplinares em classes de alfabetização, 2009, 73s. Dissertação (Mestrado em Educação). Centro de Ciências da Educação, Universidade Regional de Blumenau, Blumenau.

KNÖPKER, Mônica. Socorro, eu não consigo “dar aulas!”: Discurso sobre a disciplina na produção acadêmica contemporânea da área da educação. Dissertação (Mestrado em Educação) - Universidade do Vale do Rio dos Sinos, São Leopoldo, 2014.

KNÖPKER, Mônica. Socorro, eu não consigo “dar aulas!”: Discurso sobre a disciplina na produção acadêmica contemporânea da área da educação. Trabalho apresentado na $37^{\mathrm{a}}$ Reunião Nacional da ANPEd - 04 a 08 de outubro, UFSC - Florianópolis, 2015.

MARCHETTI, Rafaela. Violências, Conflitos e Indisciplinas:Discurso em três escolas de educação básica. 161 f. Tese de Doutorado em Educação - Universidade Federal de São Carlos, São Carlos, 2019.

MARTINS Angela Maria; MACHADO Cristiane; FURLANETTO, Ecleide Tunico. Mediação de conflitos em escolas: entre normas e percepções docentes. In: Cadernos de Pesquisa. v.46 n.161 p.736754 jul./set. 2016.

MATOS, Daniel Abud Seabra; FERRÃO, Maria Eugenia. Repetência e indisciplina: evidências de Brasil e Portugal no Pisa 2012. In: Cadernos de Pesquisa. v.46 n.161 p.736-754 jul./set. 2016.

MENDES, Fabiane. Indisciplina escolar na visão de coordenadores pedagógicos, Curitiba/PR, 2009, 126s. Dissertação (Mestrado em Educação). Departamento de Educação, Universidade Tuiuti do Paraná, Curitiba.

MONTEIRO, Leonardo. Quando o futuro é presente: uma análise sobre projetos e projeções de futuro sob a lógica da (in)disciplina no ambiente escolar. Dissertação de Mestrado - Programa de Pós-Graduação em Educação da Universidade Federal de São Carlos. São Carlos/SP; 2019. 113 f.

MONTEIRO, Leonardo. Empreendedorismo moral estudantil: uma reflexão sobre conflitos, tensões e ambiguidades no ambiente escolar. Intellectus Revista Acadêmica Digital. Jaguariúna/SP, v. 59, n.1. 2020, pp. 20-34.

MOURA, Eliana Ribeiro de. Violência da escola. Dissertação (Mestrado) - Faculdade de Educação da UNIMEP. Piracicaba; 1988.

MOURA, Dirley Aparecido de e PRODÓCIMO, Elaine. Indisciplina escolar: análise dos registros de ocorrências de indisciplinas em escolas estaduais de São Paulo. ETD-Educação Temática Digital Campinas, SP v.21 n.2 p. 513-529 abr./jun.2019.

PEREIRA, Edilaine Aparecida Santos. Indisciplina e Gênero: estudos das percepções de estudantes do ensino fundamental sobre o comportamento de indisciplina de meninas e meninos na escola. $160 \mathrm{f}$. Dissertação de Mestrado em Educação. - Universidade Federal de Ouro Preto, Mariana, 2019.

QUIRÓS, Julieta. Etnografiar mundos vívidos. Desafíos de trabajo de campo, escritura y enseñanza en antropología. Publicar. Año XII n. XVII. 2014. p. 47 -65.

RODRIGUES, Luciana Azevedo. A (in)disciplina em revista: um estudo sobre indústria cultural. (Tese de Doutorado) São Carlos: UFSCar, 2007.

SCHILLING, Flávia; ANGELUCCI, Carla Biancha. Conflitos, violências, injustiças na escola? Caminhos possíveis para uma escola justa. In: Cadernos de Pesquisa. v.46 n.161 p.736-754 jul./set. 2016. 
SILVA, Luiz Carlos Faria da. Possíveis incompletudes e equívocos dos discursos sobre a questão da disciplina. Educação \& Sociedade, Campinas, v. 19, n. 62, p. 125-150, abr. 1998.

SILVA NETO, Cláudio Marques da; BARRETTO, Elba Siqueira de Sá. (In)disciplina e violência escolar: um estudo de caso. Educação e Pesquisa, São Paulo, v. 44, p. 1-18, 2018.

SILVEIRA, Matheus Henrique da. Os "Chefes De Disciplina": Inventividade Infantil Na Década De 1930. Cadernos de Pesquisa, São Paulo, v. 51, p. 1-18, 2021.

SPOSITO, Marilia Pontes. Um breve balanço da pesquisa sobre violência escolar no Brasil. Educação e Pesquisa, São Paulo, v. 27, n. 1, p. 87-103, jan. /jun. 2001.

TÜRCKE, Christophe. Sociedade Excitada: filosofia da sensação. Campinas: Editora da Unicamp, 2010. ZECHI, Juliana Aparecida Matias. Violência e indisciplina em meio escolar: Aspectos teórico-metodológicos da produção acadêmica no período de 2000 a 2005. (Dissertação de Mestrado) Presidente Prudente: 2008 $147 \mathrm{f}$.

Submetido em maio de 2020 Aprovado em fevereiro de 2022

\section{Informações do autor}

Leonardo Henrique Brandão Monteiro

Doutorando em Educação pelo Programa de Pós-Graduação em Educação da Universidade Federal de São Carlos (PPGE-UFSCar).

E-mail: monteiro.hb.leonardo@gmail.com

ORCID: https://orcid.org/0000-0002-5323-1107

Link Lattes: http://lattes.cnpq.br/7962875409074026 